(2) Open Access Full Text Article

\title{
Long term efficacy and safety of etanercept in the treatment of psoriasis and psoriatic arthritis
}

\author{
This article was published in the following Dove Press journal: \\ Biologics:Targets and Therapy \\ 17 April 2014 \\ Number of times this article has been viewed
}

\section{Dario Kivelevitch \\ Bobbak Mansouri \\ Alan Menter}

Department of Dermatology, Baylor University Medical

Center, Dallas, TX, USA
Correspondence: Alan Menter Baylor University Medical Center, 3900 Junius Street, Suite 125,

Dallas, TX 75246, USA

Tel + I 9723547988

Fax + | 972715 |460

Email amderm@gmail.com

\begin{abstract}
Psoriasis is a chronic, immune-mediated inflammatory disease affecting both the skin and joints. Approximately $20 \%$ of patients suffer a moderate to severe form of skin disease and up to $30 \%$ have joint involvement. Standard therapies for psoriasis include topical medications, phototherapy, and both oral systemic and biological therapies whereas therapies for psoriatic arthritis include nonsteroidal anti-inflammatory drugs followed by disease modifying antirheumatic drugs and/or tumor necrosis factor (TNF)- $\alpha$ inhibitors and interleukin-12/23p40 inhibitors. Treatment of both diseases is typically driven by disease severity. In the past decade, major advances in the understanding of the immunopathogenesis of psoriasis and psoriatic arthritis have led to the development of numerous biological therapies, which have revolutionized the treatment for moderate to severe plaque psoriasis and psoriatic arthritis. Anti-TNF- $\alpha$ agents are currently considered as first line biological therapies for the treatment of moderate to severe psoriasis and psoriatic arthritis. Currently approved anti-TNF- $\alpha$ agents include etanercept, adalimumab, and infliximab for psoriasis and psoriatic arthritis as well as golimumab and certolizumab for psoriatic arthritis. In this article, we aim to evaluate the long term safety and efficacy of etanercept in psoriasis and psoriatic arthritis.
\end{abstract}

Keywords: psoriasis, psoriatic arthritis, etanercept, biological therapy, tumor necrosis factor, safety

\section{Introduction}

Psoriasis ( $\mathrm{PsO})$ is an immune-mediated chronic disease that can affect both the skin and joints. It is characterized by well demarcated, erythematous plaques with an overlying silvery scale classically distributed on the extensor surfaces, scalp, and trunk, although it can affect any area of the skin (Figure 1). Approximately 1\% to $3 \%$ of the population suffers from $\mathrm{PsO} .{ }^{1}$ Plaque $\mathrm{PsO}$ is the most common clinical form affecting approximately $80 \%$ of $\mathrm{PsO}$ patients. ${ }^{2}$ Other forms of $\mathrm{PsO}$ include guttate, pustular (generalized and localized), erythrodermic, and palmoplantar disease. PsO has been associated with a number of comorbid conditions including the metabolic syndrome, cardiovascular disease, inflammatory bowel disease, anxiety, depression, and of course psoriatic arthritis (PsA). PsA is a seronegative arthritis affecting up to $30 \%$ of patients with plaque PsO and has multiple clinical presentations. ${ }^{3,4}$ It is typically classified into five subtypes: asymmetric oligoarticular arthritis, symmetric polyarthritis, distal interphalangeal arthritis, spondylitis with or without sacroiliitis, and arthritis mutilans. Physical findings in patients with PsA can also include enthesitis and dactylitis (Figure 2). The most common form of PsA is asymmetric, although any of these types of PsA can erode and destroy 


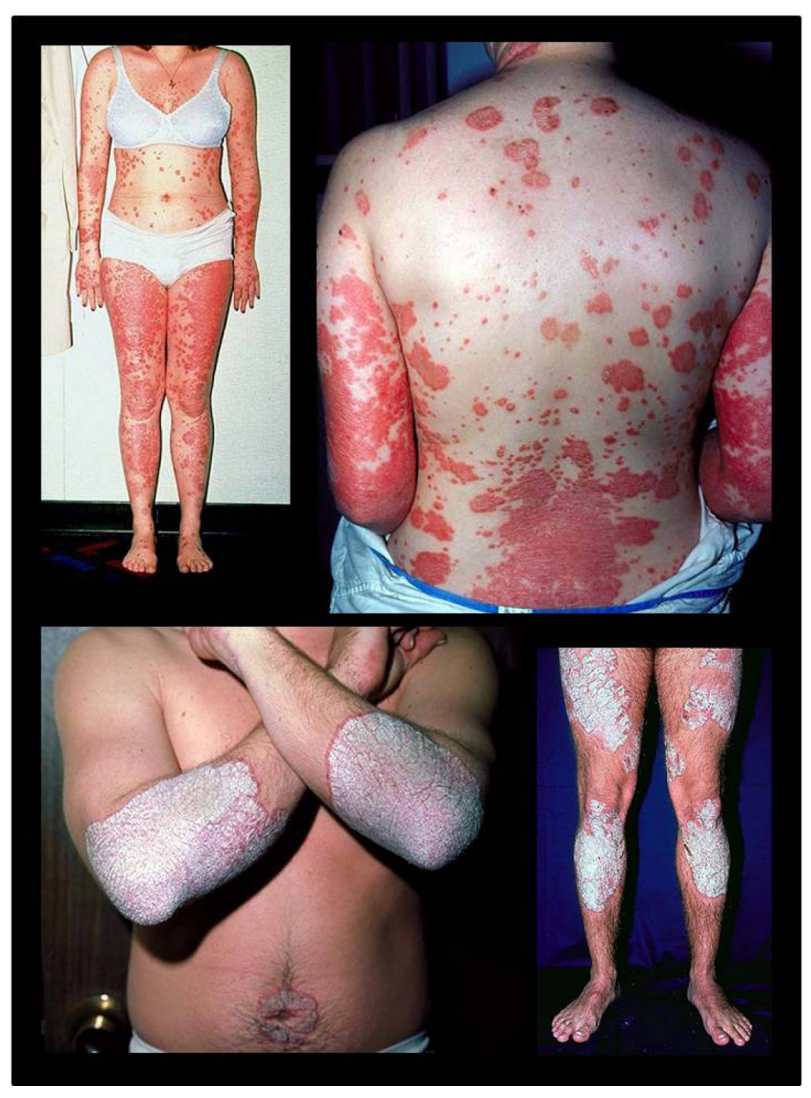

Figure I Plaque psoriasis.

Note: Classic examples of psoriasis which is characterized by well demarcated, erythematous plaques with an overlying silvery scale which can affect any area of the skin.

affected joints leading to loss of functional abilities and a considerable decline in quality of life. ${ }^{5}$

Treatment of psoriatic skin disease is based on disease severity and includes topical therapies for milder patients, phototherapy for mild to moderate disease, and oral systemic

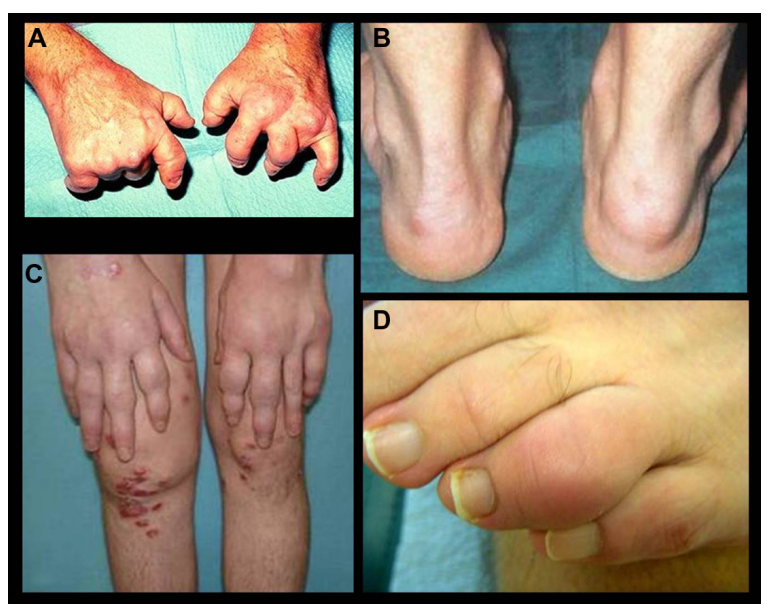

Figure 2 Psoriatic arthritis.

Notes: Patients with psoriatic arthritis displaying (A) arthritis mutilans, (B) enthesitis of the right Achilles tendon, (C) a right knee effusion and dactylitis of multiple digits, and (D) dactylitis of the fourth toe. and biological agents in patients with moderate to severe skin disease. These therapeutic strategies can be used as monotherapy or in various combinations. Similarly, PsA treatment is based on disease severity and response to therapy and includes nonsteroidal anti-inflammatory drugs for milder cases and disease modifying antirheumatic drugs, such as methotrexate and other immunosuppressants, and anti-tumor necrosis factor (TNF)- $\alpha$ as well as the newer anti-interleukin (IL)-12/23p40 agents (ustekinumab) for more severe forms.

Biological therapies have revolutionized the management of PsO and PsA. In 1984, Köhler, Milstein, and Jerne were given the Nobel Prize in Physiology or Medicine for developing this novel technology (nobelprize.org). Since then, a myriad of biological therapies have been created to treat a number of inflammatory, immune-mediated diseases. Biological therapies include monoclonal antibodies as well as recombinant fusion receptor proteins, such as etanercept.

TNF- $\alpha$ plays a major role in the pathophysiology of both PsO and PsA. ${ }^{6}$ TNF- $\alpha$ levels are elevated in psoriatic skin lesions, serum samples, and synovial fluid. ${ }^{3}$ Anti-TNF- $\alpha$ therapy has shown efficacy in treating psoriatic skin lesions, joint pain and swelling, enthesitis, and dactylitis plus the ability to improve mobility, reduce radiographic progression of disease, and influence quality of life parameters. ${ }^{7}$ TNF- $\alpha$ inhibitors which are currently approved to treat $\mathrm{PsO}$ and PsA include etanercept, adalimumab, and infliximab while two additional anti-TNF- $\alpha$ agents, golimumab and certolizumab, are only approved for use in PsA.

Etanercept was the first TNF- $\alpha$ inhibitor to be approved for use in PsO and PsA. It is a dimeric, soluble fusion protein consisting of the extracellular ligand binding portion of the TNF receptor linked to the Fc portion of human IgG1 (Figure 3). It is capable of binding and neutralizing soluble TNF and transmembrane TNF. ${ }^{8}$ Furthermore, it alters neutrophil migration and dendritic cell and T-cell maturation and migration, thus decreasing the local and systemic production of pro-inflammatory cytokines and their subsequent effects. ${ }^{6,9}$ Etanercept was synthesized in the early $1990 \mathrm{~s}^{10}$ and first tested in humans in 1992. ${ }^{11}$ In 2002 and 2004, etanercept was approved by the United States Food and Drug Administration for the treatment of PsA and in adult PsO patients, respectively. ${ }^{12}$ The recommended regimen for etanercept for patients with $\mathrm{PsO}$ is $50 \mathrm{mg}$ twice weekly for 3 months, followed by a maintenance dose of $50 \mathrm{mg}$ weekly. In children, doses of $0.8 \mathrm{mg} / \mathrm{kg}$ are used (up to a maximum of $50 \mathrm{mg}$ ) weekly. For PsA the recommended dose of etanercept is $50 \mathrm{mg}$ weekly. This article will review available data on long term efficacy and safety of etanercept in PsO and PsA. 


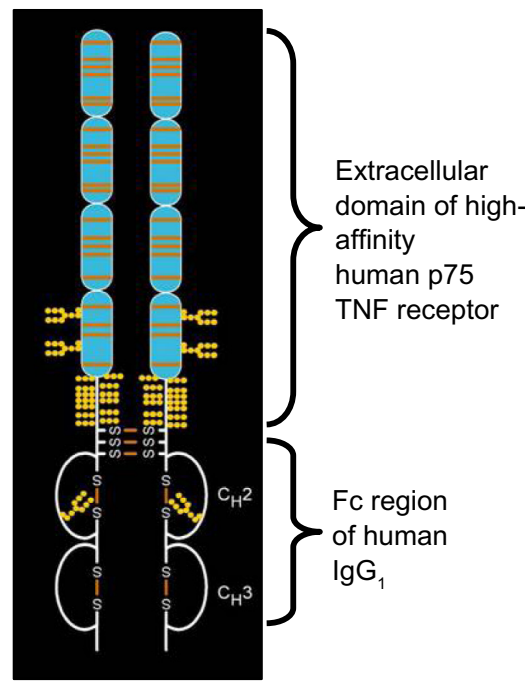

Figure 3 Etanercept molecule.

Note: Used with permission from Amgen Inc. (Thousand Oaks, CA, USA). Abbreviation: TNF, tumor necrosis factor.

\section{Etanercept efficacy in PsO}

The first multicenter, double-blind, placebo-controlled Phase III study took place in 652 patients with moderate to severe $\mathrm{PsO}$ who were randomized to either $25 \mathrm{mg}$ weekly (QW), $25 \mathrm{mg}$ twice weekly (BIW), or $50 \mathrm{mg}$ BIW of etanercept or placebo. ${ }^{13}$ At week 12, 49\%,34\%, and $14 \%$ of patients on $50 \mathrm{mg}$ BIW, $25 \mathrm{mg}$ BIW, and $25 \mathrm{mg}$ QW, respectively, achieved a $75 \%$ decrease in Psoriasis Area and Severity Index (PASI) 75 scores as opposed to $4 \%$ of patients receiving placebo $(P<0.001$ for all three comparisons). At week 24, the percentage of patients achieving PASI 75 increased to $59 \%, 44 \%$, and $25 \%$ of patients in the $50 \mathrm{mg}$ BIW, $25 \mathrm{mg}$ BIW, and $25 \mathrm{mg}$ QW groups, respectively. Twenty-eight percent of the 652 randomized study subjects did not reach PASI 50 at any point during the trial (PASI 50 nonresponders) and were enrolled in a 36-week open label extension receiving $50 \mathrm{mg} \mathrm{QW.}{ }^{14}$ During the 36-week open label extension, $72 \%$ and $38 \%$ of subjects received treatment through to at least week 48 (week 24 of open label extension) and week 60 (week 36 of open label extension), respectively. At week 36 (week 12 of open label extension), $43 \%$ of the PASI 50 nonresponders achieved PASI 50 or better response, and at week 60 (week 36 of open label extension), 55\% and $23 \%$ of subjects achieved PASI 50 and PASI 75 responses, respectively. The mean percentage improvement for this group of PASI 50 nonresponders increased from $26.6 \%$ at week 24 (open label baseline) to $49.3 \%$ at week 60 (open label week 36). The quality of life, assessed by the Dermatology Life Quality Index (DLQI) showed a mean improvement of $38.8 \%$ from the initial baseline (Table 1).

In 2007, Tyring et al published data on the 84-week open label extension ${ }^{15}$ of a Phase III, randomized, double-blind, placebo-controlled, multicenter study evaluating the efficacy and safety of $50 \mathrm{mg}$ BIW of etanercept versus placebo at 12 weeks. ${ }^{16}$ In the open label extension, 591 of the original 618 subjects received etanercept $50 \mathrm{mg}$ BIW for an additional 84 weeks, regardless of their treatment group prior

Table I Long term etanercept efficacy in psoriasis

\begin{tabular}{|c|c|c|c|c|}
\hline Study & Type & Duration & Patients & Outcomes \\
\hline Krueger et al ${ }^{14}$ & $\begin{array}{l}\text { Open label extension } \\
\text { of Phase III trial for } \\
\text { nonresponders }\end{array}$ & 60 weeks & 157 & $\begin{array}{l}\text { PASI } 50: 55 \% \text {, PASI } 75: 23 \% \text { at } \\
60 \text { weeks } \\
\text { (PASI } 50 \text { nonresponders at } \\
\text { week } 24 \text { ) }\end{array}$ \\
\hline Tyring et $\mathrm{al}^{15}$ & Phase III trial & 96 weeks & 591 & $\begin{array}{l}\text { a) Placebo/etanercept group: } \\
\text { PASI } 50 / 75 / 90: 79.1 \%, 51.6 \% \text {, } \\
\text { and } 22.8 \% \text { at } 96 \text { weeks } \\
\text { b) Etanercept/etanercept } \\
\text { group: PASI } 50 / 75 / 90: 82.6 \% \text {, } \\
51.1 \% \text {, and } 23.2 \% \text { at } 96 \text { weeks }\end{array}$ \\
\hline Leonardi et al ${ }^{19}$ & $\begin{array}{l}\text { Extension of two } \\
\text { Phase III trials }\end{array}$ & 48 up to 72 weeks & 912 & $\begin{array}{l}\text { a) } 50 \mathrm{mg} \text { QW, no dose } \\
\text { escalation group: PASI 50/75/90: } \\
90 \%, 60 \% \text {, and } 27 \% \text { at } 72 \text { weeks } \\
\text { b) } 50 \mathrm{mg} \text { BIW, dose escalation } \\
\text { group: PASI } 50 / 75 / 90: 83 \%, 43 \% \text {, } \\
\text { and } 10 \% \text { at } 72 \text { weeks }\end{array}$ \\
\hline $\begin{array}{l}\text { Paller et } \mathrm{al}^{72} \\
\text { (Pediatric) }\end{array}$ & $\begin{array}{l}\text { Open label extension } \\
\text { of Phase III trial }\end{array}$ & 96 weeks & 140 & $\begin{array}{l}\text { PASI 50/75/90: } 89 \%, 61 \% \text {, and } \\
30 \% \text { at week } 96\end{array}$ \\
\hline Papp et $\mathrm{al}^{20}$ & Post hoc analysis & Up to 4 years & 506 & $\begin{array}{l}\text { PGA clear or almost clear } \\
29.2 \% \text { and } 27.8 \% \text { at } 48 \text { months }\end{array}$ \\
\hline $\begin{array}{l}\text { Esposito et } \mathrm{al}^{70} \\
\text { (Elderly) }\end{array}$ & Retrospective & I56 weeks & 61 & PASI 75: 83.6I\% at week I56 \\
\hline
\end{tabular}

Abbreviations: PASI, Psoriasis Area and Severity Index; PGA, Physicians Global Assessment; QW, once weekly; BIW, twice weekly. 
to week 13. At week 24 (week 12 of open label extension) in the placebo/etanercept group, subjects achieved clinical improvement comparable to those patients in the original etanercept group at week 12. By week 96, PASI 50, PASI 75 , and PASI 90 response rates were $79.1 \%, 51.6 \%$, and $22.8 \%$, respectively, for the placebo/etanercept group and $82.6 \%, 51.1 \%$, and $23.2 \%$, respectively, for the etanercept/ etanercept group. PASI 75 responses reached a plateau at week 48 and of the subjects who achieved a PASI 75 response at week 48 and were reevaluated at week 96, 74.4\% maintained a PASI 75 response. Among the reasons for the observed loss of efficacy was lack of patients' adherence to the therapeutic regimen. In patients who were less than $90 \%$ adherent to therapy, responses declined by more than $20 \%$ from week 48 to 96 , in comparison with a decrease of only $10 \%$ in patients with at least $90 \%$ adherence. Of the subjects who did not achieve a PASI 75 at week 48, 17.4\% were PASI 75 responders at week 96. Mean baseline DLQI scores for the placebo/etanercept and etanercept/etanercept groups were 12.5 and 12.1, respectively, and at week 96 those values had decreased to 3.7 and 3.5, respectively, with the only statistically significant DLQI response rates occurring at week 12 between the treatment and placebo groups (77\% versus $40 \%, P<0.001$ ). Of note, during the initial 12 week study, ${ }^{16}$ fatigue and depression were assessed with the functional assessment of chronic illness therapy fatigue (FACIT-F) scale, the Hamilton Depression Rating Scale (Ham-D), and the Beck depression inventory (BDI). BDI and Ham-D improvement rates were 55\% for the etanercept group versus $39 \%$ for the placebo group $(P=0.001)$ and $43 \%$ for the etanercept group versus $32 \%$ for the placebo group $(P=0.0048)$, respectively. Furthermore, fatigue scores also improved showing at week 12 that patients receiving etanercept had an improvement in FACIT-F of 58\% compared with $43 \%$ in those receiving placebo $(P=0.0001)$. Interestingly, $18.3 \%$ of patients in this long term study were found to have anti-etanercept antibodies. However, these antibodies were determined to be nonneutralizing and did not appear to affect efficacy of treatment. Although this figure of $18.3 \%$ of subjects was higher than previously reported proportions (approximately $6 \%$ of adult patients with rheumatoid arthritis, PsA, ankylosing spondylitis, or plaque PsO), ${ }^{17}$ all prior studies also indicated that these antibodies had no effect on efficacy or safety profiles.

Two randomized, double-blind, placebo-controlled, multicenter American and global Phase III trials, ${ }^{13,18}$ were followed by an open label extension study published in 2010 by Leonardi et al. ${ }^{19}$ In this study, ${ }^{19}$ subjects initially received $50 \mathrm{mg}$ etanercept QW for the first 12 weeks. Thereafter, eligible patients could maintain the $50 \mathrm{mg}$ QW dose or escalate to $50 \mathrm{mg}$ BIW based on a lack of clinical response (inability to achieve of PASI 75, significant residual disease, or residual disease in highly aesthetic or functional areas of significance) and continue the chosen therapy for up to 72 weeks. Of the 912 subjects enrolled in the extension study, $818(89.7 \%)$ completed 48 weeks of treatment, and 485 subjects $(53.2 \%)$ completed 72 weeks of treatment. Five hundred ninety-one subjects (64.8\%) increased their dose to $50 \mathrm{mg}$ BIW at some point after week 12 while the remaining 321 subjects $(35.2 \%)$ maintained their dose at $50 \mathrm{mg}$ QW. The mean weights were higher in the increased dose versus maintained dose groups (93.2 kg versus $87.6 \mathrm{~kg}$ ). Similarly, baseline mean PASI scores of the parent (19.5 versus 17.7$)$ and extension studies (6.3 versus 8.8-8.9) were higher in the increased dose group compared to the maintained dose group. In the maintained dose group, the percentage improvement in the mean PASI score was $65 \%$ at baseline of the extension and $75 \%, 77 \%$, and $75 \%$ at weeks 12,48 , and 72 , respectively, while mean percentage of improvement in the mean PASI score for the increased dose group was $54 \%$ at baseline and $60 \%, 67 \%$, and $67 \%$ at weeks 12,48 , and 72 , respectively. Furthermore, a Physician's Global Assessment (PGA) score of 0 or 1 remained stable during the extension and was achieved by $54 \%$ and $51 \%$ of subjects at weeks 48 and 72 , respectively, in the maintained dose group. In the increased dose group, a PGA score of 0 or 1 was achieved by $28 \%$ of subjects who increased their dose at week 48 and $27 \%$ at week 72. In subjects without dose escalation, PASI 50, 75, and 90 were observed in $90 \%, 60 \%$, and $27 \%$, respectively, at week 72. In the increased dose group, PASI 50, 75, and 90 responses were observed in $83 \%, 43 \%$, and $10 \%$ of subjects, respectively, at week 72. Mean DLQI scores were improved by $55 \%$ at baseline of the extension, by $76 \%$ at 48 weeks in the maintained dose group, and by $45 \%$ and $64 \%$ at baseline and week 48, respectively, in the increased dose group.

In 2012 Papp et $\mathrm{al}^{20}$ performed a post hoc analysis on prospective efficacy and safety data for up to 4 years of etanercept use in $\mathrm{PsO}$ from a cohort of 506 Canadian patients who had participated in at least one of four previous studies. ${ }^{15,16,18,19,21}$ Subjects had received either etanercept $25 \mathrm{mg}$ BIW, $50 \mathrm{mg}$ QW, or $50 \mathrm{mg}$ BIW, based on the trial with which they had commenced therapy. This study represents the longest published experience to date as previously published data did not extend beyond 2.5 years. Effectiveness endpoints were changes from baseline DLQI and static PGA scores completed at 3 month intervals throughout the course of the 
studies. Across all studies, 29.1\% of subjects discontinued therapy prematurely. The most common reasons for premature discontinuation were withdrawal of consent and disease progression ( $11.3 \%$ and $5.5 \%$, respectively). At baseline, the mean DLQI score for subjects included in the cohort was $11.1 \pm 6.5$ and the mean static PGA score was $3.2 \pm 0.7$, with $86.8 \%$ of subjects scoring 3 to 5 points (moderate to very severe) and only one ( $0.2 \%)$ subject scoring 1 (almost clear). In the as-treated analysis, $74.3 \%$ were DLQI responders at 3 months and $75.9 \%$ achieved DLQI responses through 48 months. The proportion of subjects scoring clear or almost clear on the static PGA scale was $45.3 \%$ and $41.6 \%$ at 3 and 12 weeks, respectively. However, by 24 months, the proportion of patients had dropped to $28.6 \%$ and was maintained at $29.2 \%$ and $27.8 \%$ at months 36 and 48 , respectively. In addition, over the entire 48-month period, 141 (27.9\%) subjects had treatment gaps of greater than 8 weeks between study protocols. At 12 weeks after restarting therapy, DLQI response improved to a level similar to that seen before stopping therapy. Mean DLQI prior to stopping therapy was 3.0 with $73 \%$ of subjects as responders. At restart of therapy, mean DLQI and proportion responders were $8.6 \%$ and $29.8 \%$, respectively, and 12 weeks after restarting therapy, mean DLQI and proportion responders were $2.6 \%$ and $77.9 \%$, respectively. Static PGA response followed a similar trend after a treatment gap, as patients recovered static PGA response at 12 weeks after restarting therapy and maintained response through 24 weeks after a treatment gap. This study was the first of its kind and showed that etanercept is effective in long term treatment of $\mathrm{PsO}$, sustaining treatment response for up to 4 years.

It is worth noting that $\mathrm{PsO}$ has several associated comorbidities, including cardiovascular disease and metabolic syndrome. A retrospective study ${ }^{22}$ found that etanercept was associated with a significant reduction of myocardial infarction (MI) risk (hazard ratio, 0.53; 95\% confidence interval $[\mathrm{CI}]$ 0.31-0.92). There were no statistically significant changes of MI risk associated with the length of the treatment. A separate Italian cohort ${ }^{23}$ followed 210 patients for 24 months to assess response in metabolic parameters. Patients were assigned into three groups and treated with etanercept, adalimumab, or methotrexate. The number of PsA patients affected by metabolic syndrome did not change significantly in the different treatment groups. However, there was a trend toward a reduction in the metabolic syndrome prevalence in the etanercept and adalimumab groups at 24 months of therapy.

\section{Etanercept efficacy in PsA}

Etanercept has previously been shown to be efficacious for PsA treatment in several short term studies for up to 24 weeks. ${ }^{24-26}$ Long term efficacy was evaluated in an open label extension ${ }^{27}$ of a previously published study ${ }^{26}$ in which 169 patients continued treatment with subcutaneous etanercept $25 \mathrm{mg}$ BIW for up to 48 weeks. Subject response to therapy was determined using $20 \%$ improvement in the American College of Rheumatology scores (ACR) 20 together with radiographic progression of disease as determined by the Sharp method modified to include joints frequently affected by PsA, PsA response criteria (PsARC), and PASI scores. ACR 20 was achieved by $64 \%$ and $63 \%$ of those initially assigned to either etanercept or placebo, respectively, while $44 \%$ and $49 \%$, respectively, achieved ACR 50 (Table 2). These results were similar to those found in the initial study, and were sustained until week 48. ACR 20 and ACR 50 responses were comparable in both groups subsequent to week 12. The PsARC criteria were achieved by $80 \%$ of the patients assigned originally to etanercept. The patients assigned to placebo achieved similar results

Table 2 Long term etanercept efficacy in psoriatic arthritis

\begin{tabular}{|c|c|c|c|c|}
\hline Study & Type & Duration & Patients & Outcomes \\
\hline Mease et $\mathrm{al}^{26}$ & Phase III trial & Up to 48 weeks & 205 & $\begin{array}{l}\text { a) Placebo/etanercept group: ACR 20: } \sim 25 \% \text {, } \\
\text { ACR 50: 5\%, PsARC: } 23 \% \text { at week } 24 \\
\text { b) Etanercept group: ACR 20: } \sim 60 \% \text {, } \\
\text { ACR 50: 40\%, PsARC: } 70 \% \text { at week } 24\end{array}$ \\
\hline Mease et $\mathrm{al}^{27}$ & Extension of Phase III trial & Up to 2 years & 169 & $\begin{array}{l}\text { a) Placebo/etanercept group: ACR 20: } 63 \% \text {, } \\
\text { ACR 50: } 49 \% \text {, PsARC: } 80 \% \text { at } 96 \text { weeks } \\
\text { b) Etanercept group: ACR 20: } 64 \% \text {, } \\
\text { ACR 50: } 44 \% \text {, PsARC: } 84 \% \text { at } 96 \text { weeks }\end{array}$ \\
\hline Esposito et $\mathrm{al}^{70}$ & Retrospective & I56 weeks & 61 & $\begin{array}{l}\text { DAS44-ESR score decreased from } 5.80 \\
\text { to } 0.89 \text { at } 156 \text { weeks }\end{array}$ \\
\hline
\end{tabular}

Abbreviations: ACR 20, Improvement in the American College of Rheumatology scores by 20\%; ACR 50, Improvement in the American College of Rheumatology scores by 50\%; DAS, Disease Activity Score; DAS44-ESR, rheumatologic disease activity in 44 joints plus the erythrocyte sedimentation rate; PsARC, psoriatic arthritis response criteria. 
subsequent to12 weeks of etanercept, a result maintained throughout the length of the study. Patients originally assigned to etanercept maintained an inhibition of radiologic progression for up to 2 years of treatment. Mean adjusted Total Sharp Score from baseline to 2 years was -0.38 . In patients originally assigned to placebo, radiographic disease progression was decreased subsequent to etanercept initiation. The decrease in Total Sharp Score between the first and second year, in patients assigned first to placebo and then to etanercept, was comparable to the response observed after 1 year in patients originally treated with etanercept. In terms of radiographic disease progression, the addition of methotrexate or corticosteroids to treatment did not appear to show any significant differences. There is no clear consensus as to whether the use of methotrexate improves drug survival by decreasing adverse events (AEs). ${ }^{28-32}$ The percentage of patients showing no radiographic disease progression was higher in the group assigned to etanercept earlier. ${ }^{27}$ These studies showed long term efficacy of etanercept in treatment of PsA and its beneficial effect on prevention of further radiographic disease progression. Regarding response predictors, a recent study ${ }^{33}$ showed that higher baseline levels of complement component 3 are associated with non response to anti-TNF treatments. Results from the Danish registry ${ }^{34}$ report that high $\mathrm{C}$-reactive protein levels are associated with good treatment responses to anti-TNF agents.

\section{Safety}

The long term safety profile of etanercept has been examined in patients with moderate to severe plaque $\mathrm{PsO}$ for up to 4 years in a series of connected trials, reviews of the literature, and a registry of patients. Krueger et $\mathrm{al}^{14}$ performed an open label extension study with $\mathrm{PsO}$ patients $(\mathrm{n}=157)$ who did not achieve
PASI 50 during the initial clinical trial. Etanercept $50 \mathrm{mg}$ QW was well tolerated in the PASI 50 nonresponders for up to 60 weeks. Exposure-adjusted rates (EARs) of all AEs and infections were similar to those observed during the initial 12-week double-blind portion of the study. During the 60 week extension, most AEs were of mild to moderate intensity. Four patients had injection site reactions (3, mild intensity; 1 , moderate). Seven patients discontinued the open label study because of AEs. One patient had a serious infection (cellulitis), and one patient died approximately 1 month after the last dose of the study drug. The death was not considered to be related to study treatment ${ }^{14}$ (Tables $3-5$ ).

In a study by Tyring et al, ${ }^{15}$ subjects were treated for the first 96 weeks with $50 \mathrm{mg}$ of etanercept BIW totaling 908.9 patient-years (PY) of exposure over the course of the study. Injection site reactions occurred more frequently in patients treated with etanercept. Although overall EARs were similar among the two groups, EARs of noninfectious AEs for placebo and etanercept exposures were 418.8 and 158.0 events per 100 PY, respectively, and the EARs for serious noninfectious AEs were 6.1 and 7.7 events per $100 \mathrm{PY}$, respectively. The most common serious noninfectious AEs reported for etanercept exposure were MI (0.4 events per $100 \mathrm{PY})$, basal cell carcinoma (BCC) (0.3 events per $100 \mathrm{PY})$, and depression ( 0.3 events per $100 \mathrm{PY})$ (Table 4). None of these common, serious noninfectious AEs were reported after placebo exposure.

The EARs of infections and serious infections were similar between placebo and etanercept exposures (130.5 and 103.9 events per 100 PY and1.5 and 1.2 events per $100 \mathrm{PY}$, respectively). The most frequent type of infection was upper respiratory tract infection at 24.3 and 20.2 events per $100 \mathrm{PY}$ for placebo and etanercept exposures, respectively. Ten

Table 3 Long term safety of etanercept

\begin{tabular}{|c|c|c|c|c|c|c|c|c|}
\hline Study & Disease & Duration & Patients & $\begin{array}{l}\text { AEs } \\
\text { (noninfectious) }\end{array}$ & $\begin{array}{l}\text { SAEs } \\
\text { (noninfectious) }\end{array}$ & Infections & $\begin{array}{l}\text { Serious } \\
\text { Infections }\end{array}$ & Deaths \\
\hline $\begin{array}{l}\text { Krueger } \\
\text { et } \mathrm{al}^{14}\end{array}$ & Psoriasis & 60 weeks & 157 & 212 & 14 & 183 & I (cellulitis) & I \\
\hline $\begin{array}{l}\text { Tyring } \\
\text { et } \text { al }^{15}\end{array}$ & Psoriasis & 96 weeks & 591 & $\begin{array}{l}\text { I58/I00 patient- } \\
\text { years }\end{array}$ & $\begin{array}{l}7.7 / 100 \text { patient- } \\
\text { years }\end{array}$ & $\begin{array}{l}103.9 / 100 \text { patient- } \\
\text { years }\end{array}$ & $\begin{array}{l}\text { I.2/100 patient- } \\
\text { years }\end{array}$ & $\begin{array}{l}0.2 / 100 \text { patient- } \\
\text { years }\end{array}$ \\
\hline $\begin{array}{l}\text { Leonardi } \\
\text { et al }{ }^{19}\end{array}$ & Psoriasis & $\begin{array}{l}48 \text { up to } \\
72 \text { weeks }\end{array}$ & 912 & $\begin{array}{l}135.7 / 100 \text { patient- } \\
\text { years }\end{array}$ & $\begin{array}{l}5.6 / 100 \text { patient- } \\
\text { years }\end{array}$ & $\begin{array}{l}95.2 / 100 \text { patient- } \\
\text { years }\end{array}$ & $\begin{array}{l}1.6 / 100 \text { patient- } \\
\text { years }\end{array}$ & I \\
\hline $\begin{array}{l}\text { Pariser } \\
\text { et } \mathrm{al}^{35}\end{array}$ & Psoriasis & $\begin{array}{l}\text { Up to } \\
\text { I } 44 \text { weeks }\end{array}$ & 4,410 & $\begin{array}{l}194 / 100 \text { patient- } \\
\text { years }\end{array}$ & $\begin{array}{l}6.7 / 100 \text { patient- } \\
\text { years }\end{array}$ & $\begin{array}{l}97.8 / 100 \text { patient- } \\
\text { years }\end{array}$ & $\begin{array}{l}\text { I.2/100 patient- } \\
\text { years }\end{array}$ & 13 \\
\hline $\begin{array}{l}\text { Papp } \\
\text { et } \mathrm{al}^{20}\end{array}$ & Psoriasis & $\begin{array}{l}\text { Up to } \\
4 \text { years }\end{array}$ & 506 & 1,914 & 90 & $\begin{array}{l}96.9 / 100 \text { patient- } \\
\text { years }\end{array}$ & $\begin{array}{l}0.9 / 100 \text { patient- } \\
\text { years }\end{array}$ & 2 \\
\hline $\begin{array}{l}\text { Kimball } \\
\text { et } \mathrm{al}^{36}\end{array}$ & Psoriasis & $\begin{array}{l}\text { Up to } \\
3 \text { years }\end{array}$ & 2,511 & - & 208 & - & 82 & 30 \\
\hline
\end{tabular}

Abbreviations: AEs, adverse events; SAEs, severe adverse events. 


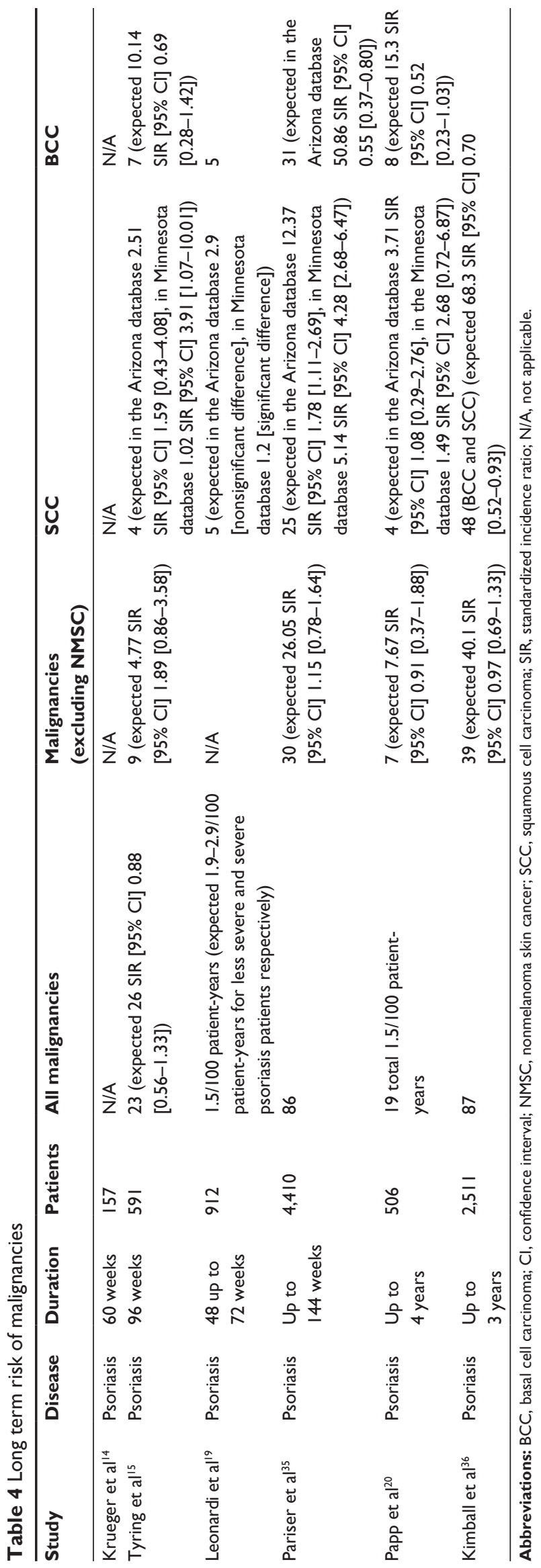

patients reported serious infections during the open label period, including two patients with cellulitis. Viral meningitis was the only serious infection considered possibly related to the study drug by the investigator. ${ }^{15}$ The EARs of AEs did not increase with longer term exposure to etanercept. Two deaths occurred during the study. One patient died of cardiac arrest 11 months after initiating etanercept therapy. The second patient died of a suspected MI approximately 10 months after initiating etanercept therapy. The latter event was reported as having a reasonable possibility to be related to the investigational product. The observed number of malignancies in this study did not significantly differ (standardized incidence ratio 0.88 ; $95 \%$ CI $0.56-1.33$ ) from the expected number seen in the psoriatic population who had severe disease and who were receiving systemic therapy. Two patients experienced worsening of heart failure, one of which was considered to be possibly related to the investigational product. No events of demyelination, tuberculosis, or opportunistic infection were reported. ${ }^{15}$

In the Leonardi et a $\mathrm{l}^{19}$ open label extension study, etanercept was generally well tolerated. The study showed serious infections rates of 1.9 and 0.9 events per $100 \mathrm{PY}$ in the $50 \mathrm{mg}$ BIW and in the $50 \mathrm{mg}$ QW group, respectively. Nevertheless, no significant differences in EARs of AEs, severe adverse events (SAEs), or infections were observed between patients who increased their dose of etanercept to $50 \mathrm{mg}$ BIW versus those who maintained their dose at $50 \mathrm{mg}$ QW. Seventeen serious infections occurred in 12 patients during the extension study. The most common serious infections were three events of pneumonia in the $50 \mathrm{mg}$ QW group and two events of cellulitis in the group that increased the dose. Fifty-nine serious noninfectious AEs occurred in 46 patients during the extension study. The most common serious noninfectious events were two events of subdural hematoma in the QW group and two events of MI and nephrolithiasis in the $50 \mathrm{mg}$ BIW group. No cases of tuberculosis, opportunistic infection, demyelinating diseases, or lymphoma were reported during the extension study. The rate of all malignancies in this study was 1.5 events per $100 \mathrm{PY}$ and a comparable rate of malignancies was reported in the Medicaid program (1.9 events per $100 \mathrm{PY}$ for patients with less severe $\mathrm{PsO}$ and 2.9 events per $100 \mathrm{PY}$ for patients with severe $\mathrm{PsO}) .{ }^{19}$ The number of observed squamous cell carcinomas (SCCs) was not significantly different from the expected number in the Arizona-based data (a highly sun-exposed population), but it was significantly higher than the expected number in the Minnesota-based data (a less sun-exposed population). ${ }^{19}$ The number of observed BCCs was significantly lower 
Table 5 Events of medical interest

\begin{tabular}{|c|c|c|c|c|c|c|c|c|}
\hline Study & Disease & Duration & Patients & CHF & Demyelination & Lymphoma & $\begin{array}{l}\text { Oportunistic } \\
\text { infection }\end{array}$ & TB \\
\hline Krueger et al ${ }^{14}$ & Psoriasis & 60 weeks & 157 & 0 & 0 & 0 & 0 & 0 \\
\hline Tyring et $\mathrm{al}^{15}$ & Psoriasis & 96 weeks & 591 & 2 & 0 & I & 0 & 0 \\
\hline Leonardi et al ${ }^{19}$ & Psoriasis & $\begin{array}{l}48 \text { up to } \\
72 \text { weeks }\end{array}$ & 912 & 0 & 0 & 0 & 0 & 0 \\
\hline Pariser et $\mathrm{a}^{35}$ & Psoriasis & $\begin{array}{l}\text { Up to } \\
\text { I } 44 \text { weeks }\end{array}$ & 4,410 & 7 & 2 & I & $\begin{array}{l}\text { I (esophageal } \\
\text { candidiasis) }\end{array}$ & 0 \\
\hline Papp et $\mathrm{a}^{20}$ & Psoriasis & Up to 4 years & 506 & I & 0 & 0 & 0 & 0 \\
\hline Kimball et a ${ }^{36}$ & Psoriasis & Up to 3 years & 2,511 & 0 & 6 & $\begin{array}{l}2 \text { (expected } \\
2.3 \text { SIR }[95 \% \mathrm{Cl}] \\
0.88[0.1 \mathrm{I}-3.17])\end{array}$ & 0 & 0 \\
\hline
\end{tabular}

Abbreviations: $\mathrm{CHF}$, congestive heart failure; $\mathrm{Cl}$, confidence interval; SIR, standardized incidence ratio; TB, tuberculosis.

than the expected number in the Arizona-based study. ${ }^{19}$ Nonneutralizing antibodies to etanercept were detected in $15.2 \%$ of patients. The safety of etanercept appeared to be similar in patients who tested positive for antibodies to etanercept when compared with those who tested negative. ${ }^{19}$ In a long term review, Pariser et al analyzed short and long term safety of etanercept to determine the associated risk with higher doses or extended exposure. ${ }^{35}$ The study involved 4,410 patients and the total number of years of exposure was 4,775.1. The rates of noninfectious and infectious AEs did not increase as the dose of etanercept increased. Moreover, the rates of AEs did not increase over time. The rates of serious noninfectious and infectious AEs were similar between the etanercept treatment groups analyzed; they were also stable over time and the $\mathrm{AE}$ rates reported in the long term analyses are consistent with those reported in the short term analyses. The most commonly reported noninfectious AEs were headache, arthralgia, injection site hemorrhage, and back pain. The most commonly reported infectious AEs were upper respiratory tract infection, nasopharyngitis, sinusitis, and influenza. Data analysis with respect to malignancies showed an increased risk for developing SCC.

The Papp et al ${ }^{20}$ post hoc study analyzed a total of 1305.4 PY of etanercept exposure. The EARs for all AEs and SAEs were 243.5 and 7.8 events per 100 PY, respectively. The EAR for all AEs was decreased for every year on therapy, although the rates of SAEs were sustained. The most common SAE included MI ( 0.6 events per 100 PY) and BCC ( 0.3 events per $100 \mathrm{PY})$. The rate of SAE occurred at a rate smaller than 1.0 event per $100 \mathrm{PY}$ of exposure. The EAR for all infectious and serious infectious AE at study completion was 96.9 and 0.9 events per $100 \mathrm{PY}$, respectively. Infection rates were similar while on etanercept therapy, regardless of the dose received. No cases of tuberculosis or opportunistic infections were reported. Nineteen malignancies (EAR of
1.5 per $100 \mathrm{PY}$ ) were reported at study completion and were not considered to be related to etanercept. The incidence rate of all malignancies, excluding nonmelanoma skin cancer (NMSC), observed at study completion was consistent with the expected rate in the general population. No statistically significant difference was seen between the observed and expected rates of BCC and SCC with either comparator database. EARs for all reported cardiovascular events $(n=37)$ and serious cardiovascular events $(n=22)$ were 2.8 and 1.7 events per $100 \mathrm{PY}$, respectively. There was no apparent association of MI or cerebrovascular accident with respect to length of exposure to etanercept. Two other deaths were reported in the cohort.

The OBSERVE-5 interim analysis evaluated data from 2,511 patients initially enrolled in a registry for up to 3 years. ${ }^{36}$ A total of 145 patients discontinued etanercept because of one or more AEs; the most common of these events were cellulitis $(\mathrm{n}=8)$, pneumonia $(\mathrm{n}=8)$, hypoesthesia $(\mathrm{n}=6)$, paresthesia $(\mathrm{n}=5)$, dyspnea $(n=4)$, and worsening $\mathrm{PsO}(\mathrm{n}=4)$. Thirty patients died during the follow-up period. However, the relationship of these deaths to etanercept was thought to be unrelated to etanercept. A total of 290 patients had one or more SAEs, including 82 patients with one or more serious infectious events and 61 patients with one or more serious infectious events requiring hospitalization. A total of 459 patients had one or more events of medical interest. The number of events of NMSC, lymphoma, and all cancers combined excluding NMSC and serious infectious events requiring hospitalization in this registry was not higher than that expected for patients with PsO using nonbiologic systemic therapies when compared to data from a large administrative health claims database ${ }^{36}$ Four-year data from this registry is pending publication.

Several studies have also evaluated safety and efficacy of retreating patients after discontinuing etanercept. One study with 2,546 patients evaluated continuous versus interrupted 
treatment with etanercept $50 \mathrm{mg}$ weekly after 12 weeks of treatment with etanercept $50 \mathrm{mg}$ BIW. ${ }^{37}$ The primary endpoint was a PGA $\leq 2$, and loss of response was defined at PGA $>2$. In the interrupted treatment group, patients were restarted after loss of response. The proportion of responders was higher in the continuous treatment group $(71.0 \%$ versus $59.5 \%, P<0.0001)$ with a similar rate of AEs and SAEs in both groups. A separated trial evaluated interruption of etanercept therapy after 24 weeks and showed that after 12 weeks of retreatment, severity scores were similar to those initially obtained in the first 12 weeks of treatment. ${ }^{38}$ Treatment was restarted after loss of $50 \%$ of PASI response seen previously at week 24. A post hoc analysis evaluated the retreatment response of 226 moderate to severe $\mathrm{PsO}$ patients. ${ }^{39}$ Patients were treated with etanercept $50 \mathrm{mg}$ BIW and discontinued treatment after 12 weeks or upon achieving PGA $\leq 2$. Treatment with etanercept $25 \mathrm{mg}$ BIW was restarted for up to 24 weeks or after achieving a PGA score of $\geq 3$. Eighty-three percent of the patients recaptured a clinical response of a PGA $\leq 2$ after retreatment. No safety concerns appeared to be associated with retreatment and no events of special medical interest (eg, tuberculosis, histoplasmosis, or demyelinating disease) were reported (Table 5).

In two large PsA trials, ${ }^{26,27}$ subjects showed AEs and infections at similar rates in both the etanercept and placebo groups during the initial 24 week period. Most events were of mild or moderate intensity. SAEs occurred in four patients in the etanercept group and included chest pain, renal calculus, syncope, and multiple sclerosis. In the placebo group, four patients experienced SAEs, including one patient who died. Laboratory abnormalities were of mild or moderate intensity during the study. During the 24-week open label extension, AEs and infections occurred at comparable or lower rates than those observed during the initial 24 weeks, with no deaths reported. No anti-etanercept antibodies were detected in any patient in the study. During the 48 weeks of the extension study, there were also no deaths. SAEs were reported in 19 patients. All were considered unrelated to etanercept except for one patient who developed pneumonia. Rates per PY of upper respiratory infection, sinusitis, urinary tract infection, flu syndrome, pharyngitis, and bronchitis were similar to those observed during the randomized phase of the study. Injection site reactions occurred in $10 \%$ of patients in the original etanercept group, compared with $27 \%$ of patients in the original placebo group. All were mild or moderate in severity. Overall, rates of AEs during the maintenance and open label periods were similar to or lower than those observed during the first 24-week double-blind treatment. ${ }^{27}$
Among the AEs reported in several studies, new onset or paradoxical exacerbations of $\mathrm{PsO}$ have been reported with all TNF- $\alpha$ inhibitors, including etanercept. ${ }^{40,41}$ In patients without $\mathrm{PsO}$ (eg, rheumatoid arthritis), one study reported that etanercept had the lowest rate of new onset PsO of all of the anti-TNF therapies. ${ }^{42}$ It is important to notice that despite these results, medically important events that have been reported with anti-TNF therapies, include, among others, demyelinating diseases, opportunistic infections, and tuberculosis (Table 5). ${ }^{17}$ Over the past decade, several registries across the world have gathered long term safety data on the use of biologics in different diseases. The British Society for Rheumatology Biologics Register reported data about the efficacy and safety of TNF- $\alpha$ inhibitors (etanercept, infliximab, and adalimumab) in PsA. ${ }^{43}$ Patients treated with etanercept $50 \mathrm{mg} /$ week $(\mathrm{n}=333)$ had an improvement of mean Disease Activity Score (DAS) 28 from 6.1 at baseline to 3.3 at 18 months. SAEs in this cohort were not separated by specific treatment. The incidence rate ratios of the TNF- $\alpha$ group when compared with controls was not increased (0.9; 95\% CI 0.8-1.3). The Spanish registry of biological therapies in rheumatic diseases (BIOBADASER) reported safety findings concerning the use of biologics in several publications. ${ }^{44,45}$ Their findings showed that AEs related to administration (ARR) of TNF- $\alpha$ antagonists are more common with infliximab (ARR rate of 28 per 1,000 PY) when compared to etanercept or adalimumab (ARR rate of 0.2 per 1,000 PY). Up until 2008, there were three reported cases of demyelinating disease in PsA patients treated with TNF- $\alpha$ inhibitors, none of which was related to etanercept. According to BIOBADASER 2.0, PsA did not increase the risk of developing cancer in patients exposed to TNF- $\alpha$ inhibitors $(n=727$ patients, bivariate incidence rate ratio 0.97; 95\% CI 0.49-1.92). ${ }^{45}$

\section{Etanercept combination treatment and comparative studies Phototherapy}

The use of etanercept in combination with ultraviolet B (UVB) phototherapy for treating $\mathrm{PsO}$ has been evaluated in several short term trials. ${ }^{46-49} \mathrm{~A} 12$-week open label study evaluated the efficacy of etanercept $50 \mathrm{mg}$ BIW in combination with narrow band UVB (NBUVB) phototherapy in 86 patients. At week $12,58.1 \%$ of subjects achieved PASI 90 response and $84.9 \%$ of subjects achieved PASI $75 .{ }^{46}$

A separate trial comparing the response to etanercept monotherapy versus etanercept plus NBUVB in 13 patients found the reduction in the modified PASI was significantly 
higher in the etanercept plus NBUVB group $(P=0.011$, $95 \% \mathrm{CI}-19 \%$ to $-3 \%$ ) over a 6 week period. ${ }^{47}$

In addition, a retrospective study comparing the efficacy of psoralen plus ultraviolet A (PUVA) light versus etanercept found PUVA responses to be higher than those of etanercept (PASI 90: 69\% and 29\%, PASI 75: 86\% and 39\%, and PASI 50: $89 \%$ and $84 \%$ for PUVA and etanercept, respectively). ${ }^{50}$ The limitations of this study include the number of patients (PUVA $n=118$ and etanercept $n=38$ ), the retrospective design, and treatment length (12 weeks for etanercept and treatment completion for PUVA). It has been previously established that long term PUVA therapy ( $>250-300$ treatments) increases the risk of NMSC (adjusted relative risk 8.6, 95\% CI 4.9-15.2) ${ }^{51}$ and melanoma (relative risk 5.4, 95\% CI 2.2-11.1). ${ }^{52}$ As such, although the combination of phototherapy and etanercept can be clinically useful, this combination should be recommended only for short term use to avoid increasing the risk of skin malignancies. ${ }^{53}$

\section{Methotrexate}

Methotrexate is the most widely used systemic treatment for PsO. Several studies have evaluated its use in conjunction with etanercept. A 24-week randomized, controlled trial assessed the combination of etanercept plus methotrexate to treat PsO. ${ }^{54}$ At week 24, PASI 75 was achieved in $77.3 \%$ versus $60.3 \%(P<0.0001)$ of patients in the etanercept plus methotrexate versus the etanercept monotherapy group, respectively. ${ }^{54}$ Although the $\mathrm{AE}$ rate was higher in the combination group, the combination therapy proved to be safe and more effective than monotherapy. ${ }^{54}$

A separate trial of 440 subjects with PsA evaluated the efficacy of the combination of anti-TNF agents (etanercept, infliximab, and adalimumab) and methotrexate. ${ }^{55}$ Of the 440 subjects, 170 received anti-TNF monotherapy while 270 received an anti-TNF therapy plus methotrexate. The study did not show a significant clinical difference (DAS 28 and ACR) between the two groups after 12 months. This study also showed drug survival was significantly better in the anti-TNF plus methotrexate (MTX) group during the first 2 years of treatment and did not show statistical significance at year $3(P=0.07)$. A stratified analysis of the three anti-TNF agents used in the study showed statistically significant differences between the monotherapy and the MTX comedication groups in patients receiving infliximab and adalimumab, favoring comedication. These differences in drug survival were not seen in both groups treated with etanercept alone or when combined with MTX.
A second study in subjects with PsA compared radiographic progression between patients treated with antiTNF- $\alpha$ agents versus methotrexate monotherapy. ${ }^{56} \mathrm{~A}$ total of 65 patients were treated with TNF- $\alpha$ inhibitors, of which 46 received etanercept compared to 70 patients who were treated with methotrexate. TNF- $\alpha$ inhibitors were more efficacious than methotrexate in the inhibition of radiographic joint damage progression ( $88 \%$ versus $61 \%, P=0.005) .{ }^{56}$

\section{Cyclosporine}

In a clinical study from 2010, seven patients with recalcitrant $\mathrm{PsO}$ were treated with a combination of etanercept and cyclosporine $200 \mathrm{mg}$ daily with a 93.2\% PASI improvement (mean time 56.5 weeks). There were no reports of SAEs during this trial. ${ }^{57}$

A separate 24-week open label study added concomitant cyclosporine $3 \mathrm{mg} / \mathrm{kg}$ /day in PsA patients whose joint symptoms had improved on etanercept monotherapy but whose PASI scores were still greater than $10 .{ }^{58}$ After 24 weeks of combined treatment, nine of these eleven patients achieved PASI 75.

Another study in subjects with PsA evaluated etanercept plus cyclosporine versus etanercept plus methotrexate for maintaining clinical control. ${ }^{59}$ After 6 months, the study showed no significant difference in the mean decrease of DAS 28 with the two associations (etanercept plus cyclosporine $2.64 \pm 0.66$ versus etanercept plus methotrexate 2.32 \pm 0.74 , $P=0.22$ ). Also, no significant difference in SAEs between the two treatment groups was found, except, not surprisingly, for hypertension, which was statistically more frequent in the etanercept plus cyclosporine group.

\section{Acitretin}

A 24-week randomized, controlled, investigator-blinded trial compared the efficacy of etanercept $25 \mathrm{mg}$ BIW, acitretin $0.4 \mathrm{mg} / \mathrm{kg}$ daily, or etanercept $25 \mathrm{mg}$ QW plus acitretin $0.4 \mathrm{mg} / \mathrm{kg}$ daily for $\mathrm{PsO}$ treatment in 62 patients. ${ }^{60} \mathrm{At}$ 24 weeks, PASI 75 response was achieved in $45 \%, 44 \%$, and $30 \%$ of patients in the etanercept, etanercept plus acitretin, and the acitretin groups, respectively $(P=0.001$ for both etanercept groups when compared with acitretin alone). No SAEs were reported. ${ }^{60}$

\section{Comparative studies with other biological agents}

Several comparative studies have analyzed short term efficacy of different biological agents compared to etanercept in the treatment of PsO. ${ }^{7,61-63}$ A 2011 meta-analysis evaluated randomized controlled trials published up to 2008 comparing the efficacy 
of infliximab, ustekinumab, adalimumab, etanercept, and efalizumab in the treatment of moderate to severe PsO. ${ }^{7}$ Based on an indirect comparison, predicted mean probability of achieving a PASI 75 of infliximab was $80 \%$, ustekinumab $90 \mathrm{mg}$ was $74 \%$, ustekinumab $45 \mathrm{mg}$ was $69 \%$, adalimumab was $58 \%$, etanercept $50 \mathrm{mg}$ BIW was 52\%, etanercept $25 \mathrm{mg}$ BIW was $39 \%$, efalizumab was $26 \%$, and placebo was $4 \%$.

A 2010 study in 903 moderate to severe PsO patients showed that at week 12 , PASI 75 was achieved by $73.8 \%$ of patients who received ustekinumab $90 \mathrm{mg}$ and by $67.5 \%$ of patients who received ustekinumab $45 \mathrm{mg}$ when compared with $56.8 \%$ of those who received etanercept $(P=0.01$ and $P<0.001$, respectively). ${ }^{62}$

In the PsA literature, a comparative review evaluated etanercept, adalimumab, infliximab, and golimumab efficacy in PsA treatment. ${ }^{64}$ No significant differences were found in ACR 20 responses to the four drugs after 24 weeks.

In addition, a large multicenter observational study evaluated the survival rate of anti-TNF- $\alpha$ treatments for PsO. ${ }^{65}$ From a total of 650 patients, etanercept showed a longer survival (mean 51.4 months, $P<0.001$ ) as compared to infliximab (36.8 months) and adalimumab (34.7 months). Treatment discontinuation due to primary and secondary inefficacy was observed in $5.2 \%$ and $14.5 \%$ of patients, respectively, whereas discontinuation due to AEs was reported in 29 subjects (4.5\%). ${ }^{65}$ These results differ from those found in the Danish study from the Danish nationwide database DERMBIO, in which infliximab held the longest survival rate compared to adalimumab and etanercept. $^{66}$

Lastly, at the recent Congress of the European Academy of Dermatology and Venereology, results were presented from the FIXTURE study, a randomized, double-blind, placebocontrolled, global multicenter study involving 1,306 patients with moderate to severe $\mathrm{PsO}$ who were randomized to receive either secukinumab (an IL-17A inhibitor) $300 \mathrm{mg}$ or 150 mg versus etanercept $50 \mathrm{mg}$ versus placebo. ${ }^{67}$ At week 12, $54 \%$ and $24 \%$ of patients taking secukinumab $300 \mathrm{mg}$ had achieved PASI 90 and PASI 100, respectively, as compared with $21 \%$ and $4 \%$ of etanercept patients. In addition, at week $52,65 \%$ of patients on secukinumab $300 \mathrm{mg}$ had a PASI 90 response as opposed to $33 \%$ of etanercept patients. AEs and SAEs were similar between treatment groups throughout the 52-week study, although full data have yet to be published.

\section{Special populations Geriatric}

Fleischmann et $\mathrm{al}^{68}$ assessed safety of etanercept in subjects 65 years of age or older compared with those younger than
65 utilizing data from 18 clinical trials of rheumatoid arthritis, two PsA trials, and two ankylosing spondylitis trials. After gender and exposure adjustments, no significant difference was observed between groups for AEs, SAEs, or serious infections. Militello et a $1^{69}$ analyzed data from two Phase III trials of etanercept treatment for patients with $\mathrm{PsO}$, of whom 77 patients were aged 65 years or older. The study found no statistical differences in rates of PASI 75 and DLQI changes between patients in the older and the younger groups. Rates of SAEs in this study were higher in the older group, but this difference was considered unrelated to etanercept treatment. ${ }^{69}$ Furthermore, Esposito et al retrospectively evaluated long term efficacy of etanercept in $\mathrm{PsO}$ patients older than 65 years. ${ }^{70}$ At week 156, PASI 75 was achieved in $84 \%$ of the 61 study subjects. The mean score used to asses rheumatologic disease activity in 44 joints plus the erythrocyte sedimentation rate decreased from 5.80 to 0.89 at 156 weeks of treatment. Etanercept was well tolerated during the study.

\section{Pediatrics}

Paller et al evaluated long term safety and efficacy of etanercept in pediatric patients (ages 4-17 years) with moderate to severe $\mathrm{PsO}$ in an open label extension from a previous 48 week etanercept study. ${ }^{71,72}$ Patients were dosed by weight and received etanercept $0.8 \mathrm{mg} / \mathrm{kg}$ QW. One hundred and eighty two subjects participated in the study and 140 (76.9\%) completed the study through to week 96 . PASI 50, 75, and 90 at week 96 were $89 \%, 61 \%$, and 30\%, respectively, figures that were superior to those previously discussed in the adult population study. Thus, in our obese PsO population (both adolescents and adults) weight-based dosing would be of value. ${ }^{71,72}$ After 96 weeks, etanercept was generally well tolerated. The most common AE was upper respiratory tract infections $(24.9 \%)$, nasopharyngitis $(17.1 \%)$, streptococcal pharyngitis $(12.7 \%)$, headache $(11.6 \%)$, and sinusitis $(10.5 \%)$. No deaths, severe or opportunistic infections, or malignancies were observed. The number of SAEs was similar to that reported in the initial 48 -week study. ${ }^{72}$

\section{Pregnancy and lactation}

Etanercept is labeled as category B by the US Food and Drug Administration ranking of drug use in pregnancy. There are no studies in pregnant or breastfeeding women. Data from a registry of patients with rheumatic diseases and $\mathrm{PsO}$ showed that out of 144 pregnant patients, the percentage of infants with major birth defects among all births was $8 \%$ for the etanercept exposed patients and $5.7 \%$ for the controls. ${ }^{8}$ In a case report, ${ }^{73}$ 
fetal serum from of a pregnant patient treated with etanercept $25 \mathrm{mg}$ BIW was approximately one thirtieth of the maternal levels. With respect to breastfeeding, serum concentrations of etanercept were recorded immediately after delivery and at weeks 1 and 3 postpartum. The infants' serum etanercept concentrations were 81,21 , and $2 \mathrm{ng} / \mathrm{mL}$ immediately after delivery and at weeks 1 and 3 , respectively. ${ }^{73}$ These data suggest that there are low levels of etanercept transferred to the fetus during pregnancy. However, because etanercept is a relatively large molecule, it would not be expected to be absorbed by a neonate's immature gastrointestinal system during breastfeeding. Nevertheless, given the observed mild increase in the rate of birth defects, etanercept should be used in pregnancy only if no other options are available. It is important to realize that $\mathrm{PsO}$ pregnancies do have a higher risk of side effects versus the normal population. ${ }^{74}$

\section{Conclusion}

$\mathrm{PsO}$ and $\mathrm{Ps} \mathrm{A}$ are chronic, immune-mediated inflammatory diseases associated with several comorbidities. The evidence of their impact in other organs has led to a major change in the definition of these diseases, once considered only limited to skin and/or joints. Now, both are considered systemic diseases. In the past two decades, our understanding of the pathophysiology of PsO has advanced enormously. These advances have been paralleled by the development of new, highly efficacious therapeutic options. Etanercept is one example of the new era in $\mathrm{PsO}$ therapeutics. As with any major advance in medicine, the advent of biological agents has come to fruition because of numerous large scale, multicenter randomized controlled trials to evaluate their efficacy and safety. Over the past decade, etanercept has proven to be efficacious as monotherapy or when used in combination with other PsO treatments. With any new medication, particularly one specifically targeting the immune system, rigorous attainment of safety data has been crucial in providing more appropriate guidelines for treatment. Specifically, various biologically agents have been associated with serious infections such as, tuberculosis and hepatitis B reactivation, demyelinating diseases, lymphomas, leukemia, and NMSC and should be used with caution taking every patient's specific needs into account. Nevertheless, many of these associations occurred at rates similar to those observed in the general population or at such small rates that the benefit of treating PsO patients clearly outweighs the risks mentioned. It has been two decades since etanercept's first human trials in 1993, and after almost a decade since its Food and Drug Administration approval, etanercept is still an important and valuable option in any physician's arsenal for the treatment of moderate to severe $\mathrm{PsO}$ and/or PsA.

\section{Disclosure}

BM has no conflicts of interest to report. DK has been a speaker for Abbott, and AM has sat on the advisory boards of Abbott, Amgen, Galderma, Janssen, and Wyeth, has been a consultant for Abbott, Amgen, Eli Lilly, Galderma, Janssen, LEO Pharma, Stiefel, and Wyeth, an investigator for Abbott, Allergan, Amgen, Celgene, Eli Lilly, Janssen, Novartis, Novo Nordisk, Pfizer, Stiefel, Syntrix Biosystems, and Wyeth, a speaker for Abbott, Amgen, Galderma, Janssen, LEO Pharma, and Wyeth, and has received grants and/or honoraria from Abbott, Allergan, Amgen, Celgene, Eli Lilly, Galderma, Janssen, LEO Pharma, Novartis, Novo Nordisk, Pfizer, Stiefel, Syntrix Biosystems, and Wyeth.

\section{References}

1. Griffiths CE, Barker JN. Pathogenesis and clinical features of psoriasis. Lancet. 2007;370(9583):263-271.

2. Lebwohl M. Psoriasis. Lancet. 2003;361(9364):1197-1204.

3. Villanova F, Di Meglio P, Nestle FO. Biomarkers in psoriasis and psoriatic arthritis. Ann Rheum Dis. 2013;72 Suppl 2:ii104-ii110.

4. Lloyd P, Ryan C, Menter A. Psoriatic arthritis: an update. Arthritis. 2012;2012:176298.

5. Sieper J, Rudwaleit M, Baraliakos X, et al. The Assessment of Spondylo Arthritis international Society (ASAS) handbook: a guide to assess spondyloarthritis. Ann Rheum Dis. 2009;68 Suppl 2:ii1-ii44.

6. Tracey D, Klareskog L, Sasso EH, Salfeld JG, Tak PP. Tumor necrosis factor antagonist mechanisms of action: a comprehensive review. Pharmacol Ther. 2008;117(2):244-279.

7. Reich K, Burden AD, Eaton JN, Hawkins NS. Efficacy of biologics in the treatment of moderate to severe psoriasis: a network meta-analysis of randomized controlled trials. Br J Dermatol. 2012;166(1):179-188.

8. Kerensky TA, Gottlieb AB, Yaniv S, Au SC. Etanercept: efficacy and safety for approved indications. Expert Opin Drug Saf. 2012;11(1): 121-139.

9. Tan JK, Aphale A, Malaviya R, Sun Y, Gottlieb AB. Mechanisms of action of etanercept in psoriasis. J Investig Dermatol Symp Proc. 2007;12(1):38-45.

10. Peppel K, Crawford D, Beutler B. A tumor necrosis factor (TNF) receptor-IgG heavy chain chimeric protein as a bivalent antagonist of TNF activity. J Exp Med. 1991;174(6):1483-1489.

11. Zaragoza V, Perez A, Sanchez JL, Oliver V, Martinez L, Alegre V. [Long-term safety and efficacy of etanercept in the treatment of psoriasis]. Actas Dermosifiliogr. 2010;101(1):47-53. Spanish.

12. Alwawi EA, Krulig E, Gordon KB. Long-term efficacy of biologics in the treatment of psoriasis: what do we really know? Dermatol Ther. 2009;22(5):431-440.

13. Leonardi CL, Powers JL, Matheson RT, et al; Etanercept Psoriasis Study Group. Etanercept as monotherapy in patients with psoriasis. N Engl J Med. 2003;349(21):2014-2022.

14. Krueger GG, Elewski B, Papp K, Wang A, Zitnik R, Jahreis A. Patients with psoriasis respond to continuous open-label etanercept treatment after initial incomplete response in a randomized, placebo-controlled trial. J Am Acad Dermatol. 2006;54(3 Suppl 2):S112-S119.

15. Tyring S, Gordon KB, Poulin Y, et al. Long-term safety and efficacy of $50 \mathrm{mg}$ of etanercept twice weekly in patients with psoriasis. Arch Dermatol. 2007;143(6):719-726. 
16. Tyring S, Gottlieb A, Papp K, et al. Etanercept and clinical outcomes, fatigue, and depression in psoriasis: double-blind placebo-controlled randomised phase III trial. Lancet. 2006;367(9504):29-35.

17. Enbrel (Etanercept) [package insert]. Thousand Oaks, CA: Immunex Corporation; 2013.

18. Papp KA, Tyring S, Lahfa M, et al; Etanercept Psoriasis Study Group. A global phase III randomized controlled trial of etanercept in psoriasis: safety, efficacy, and effect of dose reduction. Br J Dermatol. 2005;152(6):1304-1312.

19. Leonardi C, Strober B, Gottlieb AB, et al. Long-term safety and efficacy of etanercept in patients with psoriasis: an open-label study. $J$ Drugs Dermatol. 2010;9(8):928-937.

20. Papp KA, Poulin Y, Bissonnette R, et al. Assessment of the long-term safety and effectiveness of etanercept for the treatment of psoriasis in an adult population. J Am Acad Dermatol. 2012;66(2):e33-e45.

21. Elewski B, Leonardi C, Gottlieb AB, et al. Comparison of clinical and pharmacokinetic profiles of etanercept $25 \mathrm{mg}$ twice weekly and $50 \mathrm{mg}$ once weekly in patients with psoriasis. Br J Dermatol. 2007;156(1) $138-142$.

22. Wu JJ, Poon KY, Bebchuk JD. Association between the type and length of tumor necrosis factor inhibitor therapy and myocardial infarction risk in patients with psoriasis. J Drugs Dermatol. 2013;12(8): 899-903.

23. Costa L, Caso F, Atteno M, et al. Impact of 24-month treatment with etanercept, adalimumab, or methotrexate on metabolic syndrome components in a cohort of 210 psoriatic arthritis patients. Clin Rheumatol. Epub August 20, 2013.

24. Mease PJ, Goffe BS, Metz J, VanderStoep A, Finck B, Burge DJ Etanercept in the treatment of psoriatic arthritis and psoriasis: a randomised trial. Lancet. 2000;356(9227):385-390.

25. Mease P. Psoriatic arthritis: the role of TNF inhibition and the effect of its inhibition with etanercept. Clin Exp Rheumatol. 2002; 20(6 Suppl 28):S116-S121.

26. Mease PJ, Kivitz AJ, Burch FX, et al. Etanercept treatment of psoriatic arthritis: safety, efficacy, and effect on disease progression. Arthritis Rheum. 2004;50(7):2264-2272.

27. Mease PJ, Kivitz AJ, Burch FX, et al. Continued inhibition of radiographic progression in patients with psoriatic arthritis following 2 years of treatment with etanercept. J Rheumatol. 2006;33(4):712-721.

28. Kristensen LE, Gulfe A, Saxne T, Geborek P. Efficacy and tolerability of anti-tumour necrosis factor therapy in psoriatic arthritis patients: results from the South Swedish Arthritis Treatment Group register. Ann Rheum Dis. 2008;67(3):364-369.

29. Daly M, Alikhan A, Armstrong AW. Combination systemic therapies in psoriatic arthritis. J Dermatol Treat. 2011;22(5):276-284.

30. Spadaro A, Ceccarelli F, Scrivo R, Valesini G. Life-table analysis of etanercept with or without methotrexate in patients with psoriatic arthritis. Ann Rheum Dis. 2008;67(11):1650-1651.

31. Heiberg MS, Koldingsnes W, Mikkelsen K, et al. The comparative oneyear performance of anti-tumor necrosis factor alpha drugs in patients with rheumatoid arthritis, psoriatic arthritis, and ankylosing spondylitis: results from a longitudinal, observational, multicenter study. Arthritiis Rheum. 2008;59(2):234-240.

32. Duclos M, Gossec L, Ruyssen-Witrand A, et al. Retention rates of tumor necrosis factor blockers in daily practice in 770 rheumatic patients. $J$ Rheumatol. 2006;33(12):2433-2438.

33. Chimenti MS, Perricone C, Graceffa D, et al. Complement system in psoriatic arthritis: a useful marker in response prediction and monitoring of anti-TNF treatment. Clin Exp Rheumatol. 2012;30(1):23-30.

34. Glintborg B, Ostergaard M, Dreyer L, et al. Treatment response, drug survival, and predictors thereof in 764 patients with psoriatic arthritis treated with anti-tumor necrosis factor alpha therapy: results from the nationwide Danish DANBIO registry. Arthritis Rheum. 2011;63(2):382-390.

35. Pariser DM, Leonardi CL, Gordon K, et al. Integrated safety analysis: short- and long-term safety profiles of etanercept in patients with psoriasis. J Am Acad Dermatol. 2012;67(2):245-256.
36. Kimball AB, Pariser D, Yamauchi PS, et al. OBSERVE-5 interim analysis: an observational postmarketing safety registry of etanercept for the treatment of psoriasis. J Am Acad Dermatol. 2013;68(5): 756-764.

37. Moore A, Gordon KB, Kang S, et al. A randomized, open-label trial of continuous versus interrupted etanercept therapy in the treatment of psoriasis. J Am Acad Dermatol. 2007;56(4):598-603.

38. Gordon $\mathrm{KB}$, Gottlieb AB, Leonardi CL, et al. Clinical response in psoriasis patients discontinued from and then reinitiated on etanercept therapy. J Dermatol Treat. 2006;17(1):9-17.

39. Ortonne JP, Taieb A, Ormerod AD, et al. Patients with moderate-tosevere psoriasis recapture clinical response during re-treatment with etanercept. Br J Dermatol. 2009;161(5):1190-1195.

40. Gottlieb AB, Matheson RT, Lowe N, et al. A randomized trial of etanercept as monotherapy for psoriasis. Arch Dermatol. 2003;139(12): 1627-1632; discussion 1632.

41. Chen LA, Su LH, Chang YJ, Hsu YL, Tsai TH. New-onset psoriasis associated with etanercept therapy. J Dermatol Treat. 2010;37(4): 378-380.

42. Harrison MJ, Dixon WG, Watson KD, et al; British Society for Rheumatology Biologics Register Control Centre Consortium; BSRBR. Rates of new-onset psoriasis in patients with rheumatoid arthritis receiving anti-tumour necrosis factor alpha therapy: results from the British Society for Rheumatology Biologics Register. Ann Rheum Dis. 2009;68(2):209-215.

43. Saad AA, Ashcroft DM, Watson KD, Symmons DP, Noyce PR, Hyrich KL; BSRBR. Efficacy and safety of anti-TNF therapies in psoriatic arthritis: an observational study from the British Society for Rheumatology Biologics Register. Rheumatology. 2010;49(4): 697-705.

44. Perez-Zafrilla B, Angel Descalzo M, Carmona L; y Grupo de Estudio B BIOBADASER. [Adverse Reactions Related to the Administration of TNF Inhibitors. Analysis of a Registry of Biologic Therapy]. Reumatol Clin. 2008;4(3):90-95. Spanish.

45. Carmona L, Abasolo L, Descalzo MA, et al; BIOBADASER Study Group; EMECAR Study Group. Cancer in patients with rheumatic diseases exposed to TNF antagonists. Semin Arthritis Rheum. 2011;41(1):71-80.

46. Kircik L, Bagel J, Korman N, et al; UNITE Study Group. Utilization of narrow-band ultraviolet light $\mathrm{B}$ therapy and etanercept for the treatment of psoriasis (UNITE): efficacy, safety, and patient-reported outcomes. J Drugs Dermatol. 2008;7(3):245-253.

47. Gambichler T, Tigges C, Scola N, et al. Etanercept plus narrowband ultraviolet $\mathrm{B}$ phototherapy of psoriasis is more effective than etanercept monotherapy at 6 weeks. Br J Dermatol. 2011;164(6):1383-1386.

48. Wolf P, Hofer A, Legat FJ, et al. Treatment with 311-nm ultraviolet B accelerates and improves the clearance of psoriatic lesions in patients treated with etanercept. Br J Dermatol. 2009;160(1):186-189.

49. De Simone C, D’Agostino M, Capizzi R, Capponi A, Venier A, Caldarola G. Combined treatment with etanercept $50 \mathrm{mg}$ once weekly and narrow-band ultraviolet $\mathrm{B}$ phototherapy in chronic plaque psoriasis. Eur J Dermatol. 2011;21(4):568-572.

50. Inzinger M, Heschl B, Weger W, et al. Efficacy of psoralen plus ultraviolet A therapy vs biologics in moderate to severe chronic plaque psoriasis: retrospective data analysis of a patient registry. Br J Dermatol. 2011;165(3):640-645

51. Stern RS, Liebman EJ, Vakeva L. Oral psoralen and ultraviolet-A light (PUVA) treatment of psoriasis and persistent risk of nonmelanoma skin cancer. PUVA Follow-up Study. J Natl Cancer Inst. 1998;90(17): $1278-1284$

52. Stern RS, Nichols KT, Vakeva LH. Malignant melanoma in patients treated for psoriasis with methoxsalen (psoralen) and ultraviolet A radiation (PUVA). The PUVA Follow-Up Study. $N$ Engl $J$ Med. 1997;336(15):1041-1045.

53. Di Lernia V, Albertini G. Is antitumour necrosis factor therapy combined with ultraviolet B phototherapy safe? Br J Dermatol. 2010;162(5): $1147-1148$. 
54. Gottlieb AB, Langley RG, Strober BE, et al. A randomized, doubleblind, placebo-controlled study to evaluate the addition of methotrexate to etanercept in patients with moderate to severe plaque psoriasis. Br J Dermatol. 2012;167(3):649-657.

55. Fagerli KM, Lie E, van der Heijde D, et al. The role of methotrexate co-medication in TNF-inhibitor treatment in patients with psoriatic arthritis: results from 440 patients included in the NOR-DMARD study. Ann Rheum Dis. 2014;73(1):132-137.

56. Eder L, Thavaneswaran A, Chandran V, Gladman DD. Tumour necrosis factor alpha blockers are more effective than methotrexate in the inhibition of radiographic joint damage progression among patients with psoriatic arthritis. Ann Rheum Dis. 2013;72(4):578-582.

57. Lee EJ, Shin MK, Kim NI. A clinical trial of combination therapy with etanercept and low dose cyclosporine for the treatment of refractory psoriasis. Ann Dermatol. 2010;22(2):138-142.

58. D'Angelo S, Cutro MS, Lubrano E, et al. Combination therapy with ciclosporin and etanercept in patients with psoriatic arthritis. Ann Rheum Dis. 2010;69(5):934-935.

59. Atzeni F, Boccassini L, Antivalle M, Salaffi F, Sarzi-Puttini P. Etanercept plus ciclosporin versus etanercept plus methotrexate for maintaining clinical control over psoriatic arthritis: a randomised pilot study. Ann Rheum Dis. 2011;70(4):712-714.

60. Gisondi P, Del Giglio M, Cotena C, Girolomoni G. Combining etanercept and acitretin in the therapy of chronic plaque psoriasis: a 24-week, randomized, controlled, investigator-blinded pilot trial. Br J Dermatol. 2008;158(6):1345-1349.

61. Galvan-Banqueri M, Marin Gil R, Santos Ramos B, Bautista Paloma FJ. Biological treatments for moderate-to-severe psoriasis: indirect comparison. J Clin Pharm Ther. 2013;38(2):121-130.

62. Griffiths CE, Strober BE, van de Kerkhof P, et al; ACCEPT Study Group. Comparison of ustekinumab and etanercept for moderate-tosevere psoriasis. N Engl J Med. 2010;362(2):118-128.

63. Gottlieb AB, Leonardi C, Kerdel F, Mehlis S, Olds M, Williams DA. Efficacy and safety of briakinumab vs etanercept and placebo in patients with moderate to severe chronic plaque psoriasis. Br J Dermatol. 2011;165(3):652-660.

64. Fenix-Caballero S, Alegre-del Rey EJ, Castano-Lara R, PuigventosLatorre F, Borrero-Rubio JM, Lopez-Vallejo JF. Direct and indirect comparison of the efficacy and safety of adalimumab, etanercept, infliximab and golimumab in psoriatic arthritis. J Clin Pharm Ther. 2013;38(4):286-293.
65. Esposito M, Gisondi P, Cassano N, et al. Survival rate of anti-TNF alpha treatments for psoriasis in routine dermatological practice: a multicenter observational study. Br J Dermatol. 2013;169(3):666-672.

66. Gniadecki R, Kragballe K, Dam TN, Skov L. Comparison of drug survival rates for adalimumab, etanercept and infliximab in patients with psoriasis vulgaris. Br J Dermatol. 2011;164(5):1091-1096.

67. Langley R. Secukinumab compared with placebo and etanercept: The first 52-week head-to-head comparison of two biologics in a randomized, double-blind phase 3 study in subjects with moderate-to-severe psoriasis (FIXTURE). Oral presentation at: 22nd Congress of the European Association of Dermatology and Venereology (EADV); October 3; 2013; Istanbul, Turkey.

68. Fleischmann R, Baumgartner SW, Weisman MH, Liu T, White B, Peloso P. Long term safety of etanercept in elderly subjects with rheumatic diseases. Ann Rheum Dis. 2006;65(3):379-384.

69. Militello G, Xia A, Stevens SR, Van Voorhees AS. Etanercept for the treatment of psoriasis in the elderly. J Am Acad Dermatol. 2006;55(3): 517-519.

70. Esposito M, Giunta A, Mazzotta A, et al. Efficacy and safety of subcutaneous anti-tumor necrosis factor-alpha agents, etanercept and adalimumab, in elderly patients affected by psoriasis and psoriatic arthritis: an observational long-term study. Dermatology. 2012;225(4):312-319.

71. Paller AS, Siegfried EC, Langley RG, et al; Etanercept Pediatric Psoriasis Study Group. Etanercept treatment for children and adolescents with plaque psoriasis. $N$ Engl J Med. 2008;358(3):241-251.

72. Paller AS, Siegfried EC, Eichenfield LF, et al. Long-term etanercept in pediatric patients with plaque psoriasis. $\mathrm{J}$ Am Acad Dermatol. 2010;63(5):762-768.

73. Murashima A, Watanabe N, Ozawa N, Saito H, Yamaguchi K. Etanercept during pregnancy and lactation in a patient with rheumatoid arthritis: drug levels in maternal serum, cord blood, breast milk and the infant's serum. Ann Rheum Dis. 2009;68(11):1793-1794.

74. Cohen-Barak E, Nachum Z, Rozenman D, Ziv M. Pregnancy outcomes in women with moderate-to-severe psoriasis. J Eur Acad Dermatol Venereol. 2011;25(9):1041-1047.

\section{Publish your work in this journal}

Biologics: Targets \& Therapy is an international, peer-reviewed journal focusing on the patho-physiological rationale for and clinical application of Biologic agents in the management of autoimmune diseases, cancers or other pathologies where a molecular target can be identified. This journal is indexed on PubMed Central, CAS, EMBase, Scopus

\section{Dovepress}

and the Elsevier Bibliographic databases. The manuscript management system is completely online and includes a very quick and fair peerreview system, which is all easy to use. Visit http://www.dovepress com/testimonials.php to read real quotes from published authors. 